\title{
Anatomical and Histochemical Investigation of Urinary System in Grey Mongoose (Herpestesedwardsii) in Iraq
}

\author{
Hussein Bashar Mahmood', Abbas Lafi Batah² and Maha Abdul-Hadi Abdul-Rida Al-Abdula ${ }^{3}$ \\ 'Department of Anatomy and Histology \College of Veterinary Medicine \University of Kerala, \\ Kerbala, Iraq; hussein.81@yahoo.com \\ ${ }^{2}$ Department of Anatomy and Histology \College of Medicine\Misan University, Amaraah, Iraq; \\ abbaslafi@yahoo.com \\ ${ }^{3}$ Department of Anatomy and Histology \College of Veterinary Medicine $U$ University of Al-Qadisiyah, \\ Diwaniyah, Iraq; Muha.alabdula@Qu.edu.iq
}

\begin{abstract}
Objectives: The purposes of the present study are to provide a basic knowledge of anatomical and histochemical features, because is dearth information about mongoose and carnivores especially. Also provide information about normal clinical examinations because the renal diseases are common in carnivores. Methods/Statistical Analysis: The experiments are conducted using ten animals caught from orchards in South of Iraq. The animals euthanized by I.M of diazepam (1 mg/1 kg) with ketamine ( $30 \mathrm{mg}, 1 \mathrm{~kg}$ ). The morphological study of the target organs included shape, length, thickness, width, blood supply and relation with other. The samples were fixed in $10 \%$ buffered formalin for 48 hours and dehydrated in alcohols after that, impregnation in paraffin. The embedded blocks are cut (5) $\mu$ thick and slices stained with $\mathrm{H}$ and E, Masson's stain and PAS stain. Findings: Anatomically, the kidney covered by thin capsule of red-brown in color, bean in shape, the external surface had highly vascularize. The internal surface had dark cortex with one pyramidal rays and single papilla. There are two branches of renal artery that enter to right side; the left was received one branch. The ureter was narrow tubule extend dorsally and price the urinary bladder in lateral side. Urinary bladder was triangular in shape located in caudal region of pelvic cavity. Histologically, the renal corpuscles increased in mid-cortex, henle loop appears large in diameter than that of the descending limb and is enclosing a wider lumen. Improvement/Applications: This is first Histomorphology report of grey mongoose in Iraq and may help as a model for future studies on urinary system in human and carnivores.
\end{abstract}

Keywords: Anatomy of Urinary System, Grey Mongoose

\section{Introduction}

The grey mongoose is the most important animal used as breeding ornamental, also because this animal according to ${ }^{1}$ status listed as Least Concern. The classification of grey mongoose in Iraq includes ${ }^{2,3}$. Order: Carnivora, Family: Herpestidae, Genus: Herpestes, Species: H. edwardsii. Grey mongooses (Herpestidae) are minor, wide spread carnivores occupying various habitats from South Africa to all regions of Asia ${ }^{4}$. The ${ }^{5}$ stated that the genus of edwardsii include ten species and is considered the oldest genus within the order Carnivora ${ }^{6}$.

The Indian mongoose mostly found in southern Asia mainly India, Pakistan, Nepal, Sri Lanka and some other parts of Asia ${ }^{7}$. Also found in Saudi Arabia, Bahrain, Kuwait, India, Sri Lanka, Nepal and Indonesia, and has been introduced on Japan ${ }^{8-10}$. The urinary system is a major matter of medical research because many diseases are incurable when the kidney is roughly deterioration ${ }^{11}$. $\mathrm{In}^{12}$ describes that the urinary system is more impor-

${ }^{*}$ Author for correspondence 
tant in other clinical studies, in which for effect of drug induced poisonousness is a frequent finding in clinical studies. In $^{13}$ reported that the many of problems can be accrue in ductal epithelium for this system as renal failure especially sensitive to some of materials because of water and absorption and dynamic transference systems, which lead to accumulation of toxicants substances in the tubular duct. In ${ }^{14}$ stated that the nephron is consider a structure and effective unit of the kidney. This structure comprises from a corpuscle, proximal convoluted and straight tubules, henle loop and distal straight and convoluted tubules. The functional unit has different characteristic which vary among species of animals. In birds, the urinary system has two classes of nephrons; one small sized, without loops of henle and other is large in size with intermediary length loops. In ${ }^{15}$ mentioned that the ability of different animals to form focused urine is strictly associated with the length of the loop of henle. The kidneys are playing important metabolism in the body, such secretion of waste products from the bloodstream and absorption of water and some of materials, rule of electrolytes movement and incentive of RBC cells production. $\mathrm{In}^{16,17}$ noticed that the kidney play main role to control of blood pressure by effect of a renin, maintaining $\mathrm{pH}$ level as well as chemical stability and maintenance of fluid balance of the body.

\section{Material and Method}

Ten healthy grey mongooses of both sexes were used in this study. The average weight of the animals was (350.4) $\mathrm{gm}$. The average body length was $(54) \mathrm{cm}$. The animals were caught from orchards in south of Iraq. The grey mongooses were euthanized by IM injection of diazepam $(1 \mathrm{mg} / 1 \mathrm{~kg})$ with ketamine $(30 \mathrm{mg}, 1 \mathrm{~kg})^{18}$. The morphological study of the target organs included shape, length, thickness, width and relation with other organs. The blood supply was done by injection of latex and red color of carmine stain in aorta by catheter. These measurements were recorded in centimeter $(\mathrm{mm})$ using electric vernia. The weight was recorded in gram (gm) using the sensitive electronic balance. For histological and histochemical purposes the samples were fixed in 10\% neutral buffered formaldehyde and sectioned serially at $5 \mu \mathrm{m}$. Sections were stained with $\mathrm{H}$ and $\mathrm{E}$, PAS, Masson's trichrome for the connective tissue ${ }^{19}$.

\section{Results and Discussion}

\subsection{Kidney}

Anatomically, the present study explained that the renal system in grey mongoose consist of kidneys, ureters was narrow tubule extend dorsally form the hilus of kidney and moved caudally which price the urinary bladder in lateral side. The urinary bladder was triangular in shape located in caudal part of pelvic region (Figures 1 and 2). The kidney was appeared as bean-shape, red-brown in color, located in dorsal aspect of body adherence attachment with vertebral column. The external surface appeared rough and highly vascularized covered by thin capsule; this finding uncomfortable with ${ }^{20}$ who stated that the kidney of dog has smooth surface and thick capsule.

The internal surface of kidney includes dark cortex area separated from the medulla by subcortical zone; the medulla opened in wide pelvic region by one pyramidal rays and papilla (Figures 3 and 4). This result is akin with ${ }^{21}$ who described that the kidney in dog has single papilla. The current study recorded that the kidneys in grey mongoose don't located in same level, but noticed the right kidney moved more cranially, this finding disagreement with ${ }^{20}$ who reported that the left kidney typically somewhat more superior in position than the right in human, but in cat the right located more cranially. The left kidney situated caudally to the stomach, cecum and adjacent to the aorta while the right kidney was positioned in the shallow renal impression of the liver, lateral to the caudal venacava, this result akin with ${ }^{22}$. The kidney was received blood source laterally from aorta about (1.5-2) cm away from celiac artery. There are two branches originated from aorta extended laterally and enter the right kidney through hilus area, one of them initiated obverse away to cranial mesenteric vessels and second subdivision made about (1) $\mathrm{cm}$ from first branch. The left side was originated caudally to the right branch artery, about $(2.5) \mathrm{cm}$ back the celiac artery (Figure 5). This result was unlike with ${ }^{23}$ who found that in most of animals the renal arteries were invented a single vessel directly from the aorta.

The present study explained that the left kidney slightly longer than the right, the measurements of right and left kidney respectively was $(1.4,1.6) \mathrm{cm}$ in length, $(0.4,0.6)$ $\mathrm{cm}$ thickness, $(0.6,0.7) \mathrm{cm}$ width and $(2.5,2.7)$ gm weight (table, chart, 1). Also this study shows the ratio of weight $\mathrm{R}$ and L kidney to the body weight in (gm) about (1\%), 
while show the ratio of length, thickness, width of $\mathrm{L}$ and $\mathrm{R}$ kidney to the length of body respectively about ( $2 \%$, $3 \%),(1 \%)$ and (1\%).This disagree with earlier report ${ }^{24}$ who stated that the kidney measurements in feline should be of similar in length (Figures 6 and 7).

Histologically, the current study observes that both of right and left kidneys were surrounded by fibro connective tissues which formed delicate capsule, composed mainly of collagens fibers and spindle shaped fibroblasts. This is a disagreement with $^{24}$ (vide Table 1 ) who observed that the capsular layerin dog isthick (Figure 8). As per the present study, the kidney was composed of an outer region (cortex) and an inner region (medulla) which terminated with renal papillae. The cortex was consisted of corpuscles, convoluted proximal and distaltubules and collecting tubules; this finding is akin with ${ }^{25}$ in domestic animals (Figure 9). The cortex was extended from the capsule to the medulla showing variation in distribution of renal corpuscle from the superficial region which has little renal corpuscles to the mid-cortical region where the numbers of renal corpuscles were increased clearly and the juxtamedullary region had less renal corpuscle than the mid-cortical region; this finding seems consistent with ${ }^{26}$ who stated that the present of large number of renal corpuscles in mid-cortical area and henle have some relationship with the condensation of urine in cattle, swine, dog and cat. The medullary rays were seen penetrating the cortex (Figures 10 and 11) ${ }^{27}$. The renal corpuscles were composed of a tuft of capillaries formed the glomerulus which surrounded with a double layers of Bowman's capsule, the outer or partial layer lined by simple squamous epithelium supported by a basal lamina, the inner or visceral layer was represented by the podocytes, the glomerulus was supported by mesangial cells, between the two layers of Bowman space (Figure 12). This result was corresponding with finding of ${ }^{27,28}$ in camel. The proximal tubules were lined by simple cuboidal epithelium, the cells were acidophilic and had large centrally located nuclei and the brush border was not prominent.

The distal tubules were lined by simple cuboidal epithelium; these cells were slighter than the cells of proximal part and less acidophilic. The collecting tubules were lined with cuboidal epithelium which changes to columnar toward the tip of the pyramid. It stains weakly so it has pale appearance this disagree with ${ }^{29}$ who stated that the collecting duct has simple columnar epithelial cells with large lumen in dog (Figure 13). The current study describe the medulla of the kidney was formed from collecting duct and two regions which different in thickness, thick and thin part of the henle, the current study showing that the descending portion of medulla was thick and similar with proximal tubules in cortex area. However, the ascending part of henle loop was appeared larger and wider lumen than the descending part. There are many of capillaries of vasarecta which surrounded them usually appeared filled with blood. The collecting ducts were lined by simple cuboidal epithelium terminated with papillary duct which has the same lining. These results were corresponding partially with ${ }^{30}$ in cat and dog (Figures 14 and 15). Histochemically, the present study explained that the cortex and medulla were exhibited moderated reaction for PAS stain especially at basement membrane, also the proximal tubules appeared a positive reaction with PAS stain while the distal tubules and collecting duct which appeared negative reaction. These results similar with ${ }^{31}$ who finding that the glomerular constituents include podocytes, capillary, endothelial cells and connective tissue which were PAS positive, the descending limb of loop of henle by being strongly PAS positive (Figures 16 and 17). The current study revealed that the kidney had large amount of collagen fibers intraglomerular. Also, this study finding the present of collagen fibers in pelvic kidney and around urinary vessels, this result uncomfortable with ${ }^{32}$ that describe the rabbit kidney cortex showing a scanty interstitial connective tissue around tubules and in between the glomerular tuft of capillary (Figures 18 and 19).

\subsection{Ureter}

The wall of ureter in grey mongoose was consisted of three main layers. Mucosa, muscularis externa and adventitia, the mucosa linen by thick layer of transitional epithelium rested on lamina propria which composed of loose connective tissue rich with collagens fibers, this disagreement with $^{31}$ who stated that the rat has narrow region on the surface layer of epithelium, the muscularis externa was consisted of inner longitudinal and outer circular layer of smooth muscles surrounded by adventitia layer which composed mainly of collagens fibers, this result unakin with $^{32}$ who describe the muscularis consists of three layers of smooth fibers, arranged in three directions longitudinal internally, circular direction in middle region and outer layer directed longitudinally. These three layers 


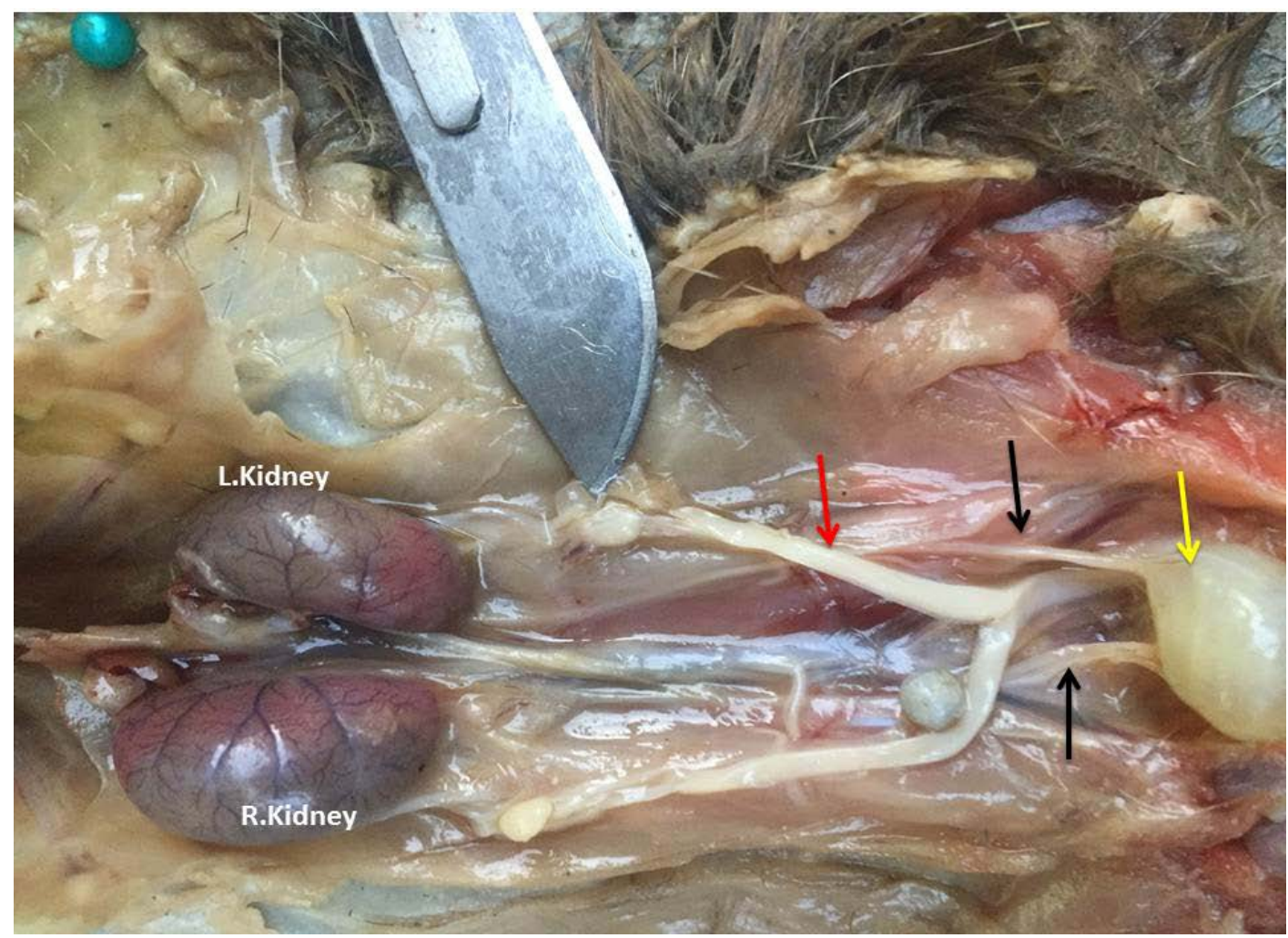

Figure 1. Urinary system showing right and left kidney, Ureter (black arrows), urinary bladder (yellow arrow) and uterus (red arrow). (Bundars et al. 2010 $)^{19}$.



Figure 2. Urinary system showing right and left kidney, ureter, urinary bladder. (Ali et al. 2014) ${ }^{20}$. 




Figure 3. Kidney of grey mongoose showing external surface had highly vascularized. (Ali et al. 2014) ${ }^{20}$.

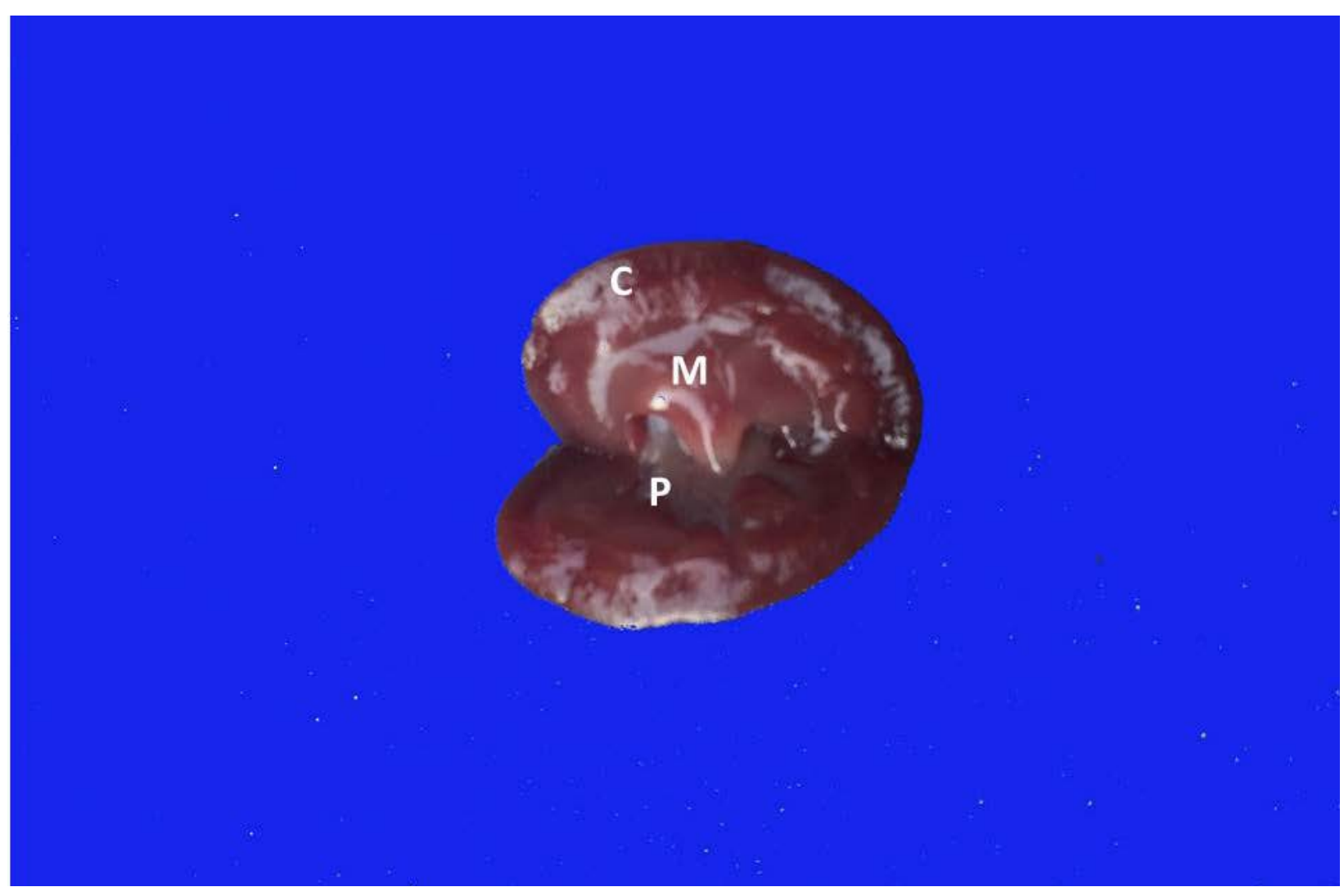

Figure 4. Kidney of grey mongoose showing internal surface, C-Cortex, M-Medulla and P-Pelvic. (Stocco et al. 2014) ${ }^{21}$. 




Figure 5. Blood supply showing two branches to the right kidney (yellow arrows) and one branch to left (black arrow). (Yoldas and Aydin, 2014)23.

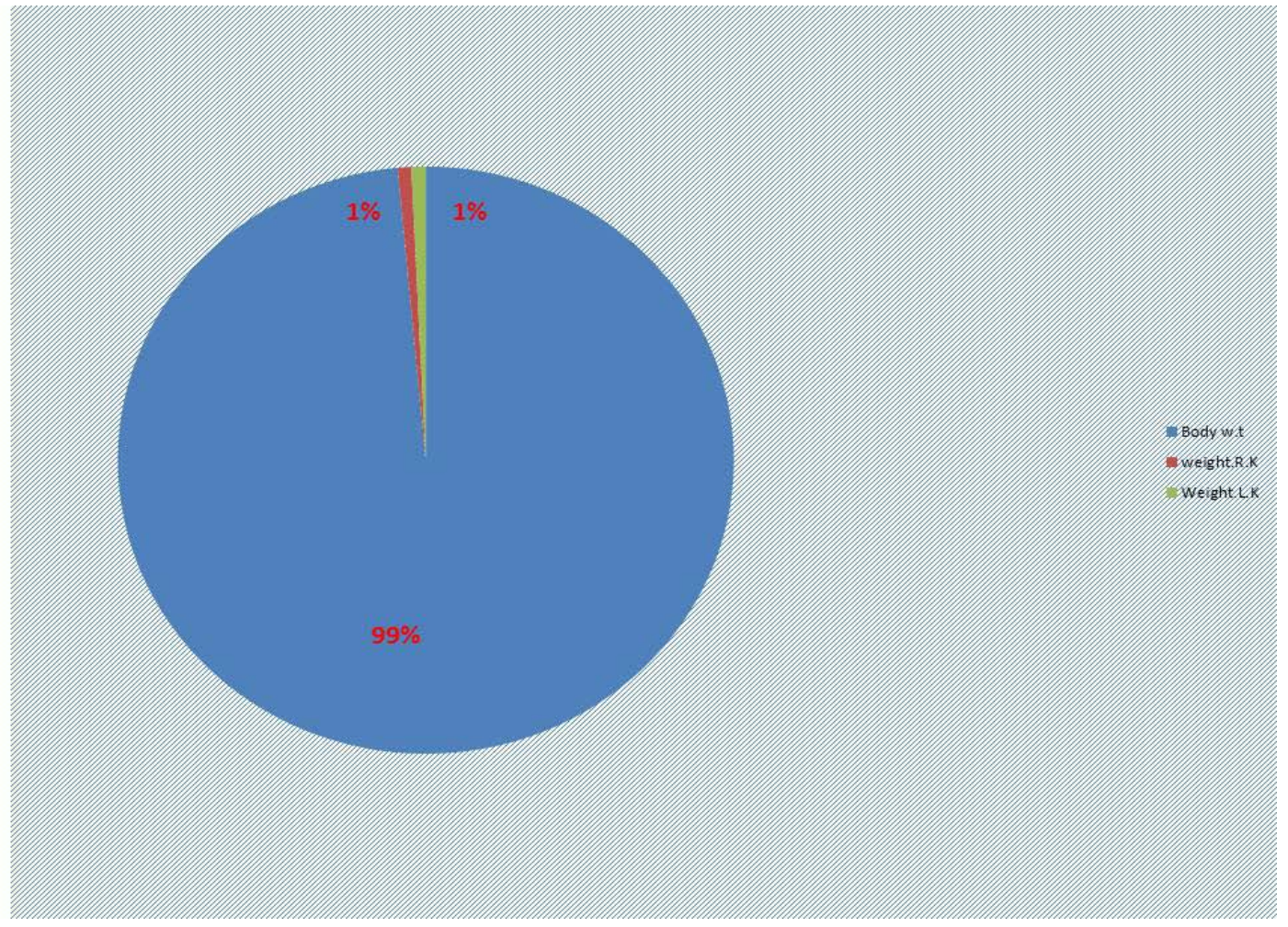

Figure 6. The ratio of weight right and left kidney to the body weight in (gm). (Larson et al. 2009) ${ }^{24}$. 




Figure 7. Ratio of the length of right and left renal to the length of body (cm). (Larson et al. 2009) ${ }^{24}$.

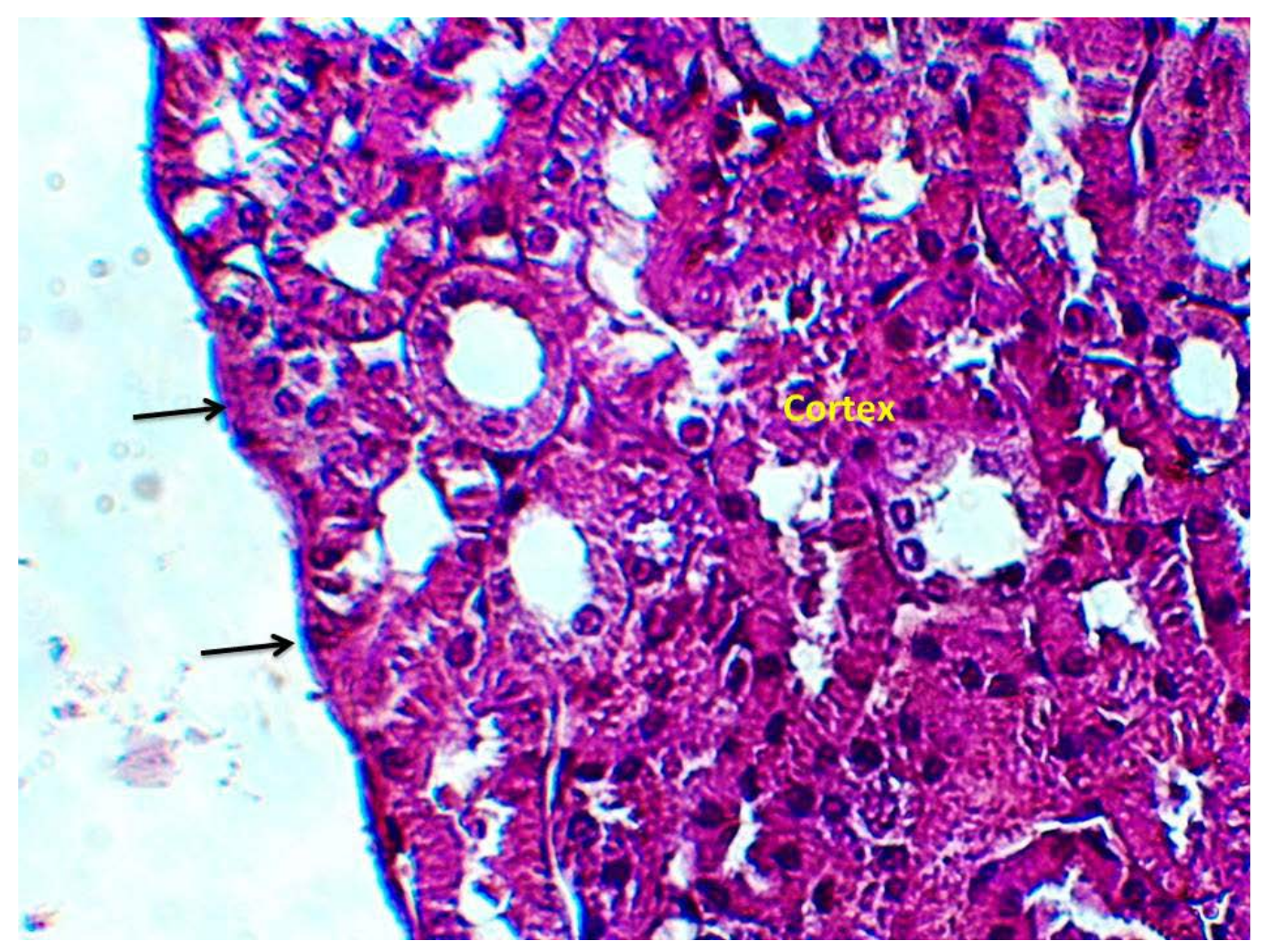

Figure 8. Kidney of grey mongoose covered by thin capsule (black arrow). H and E stain. 400X. $(\text { Hall, 1979) })^{25}$. 


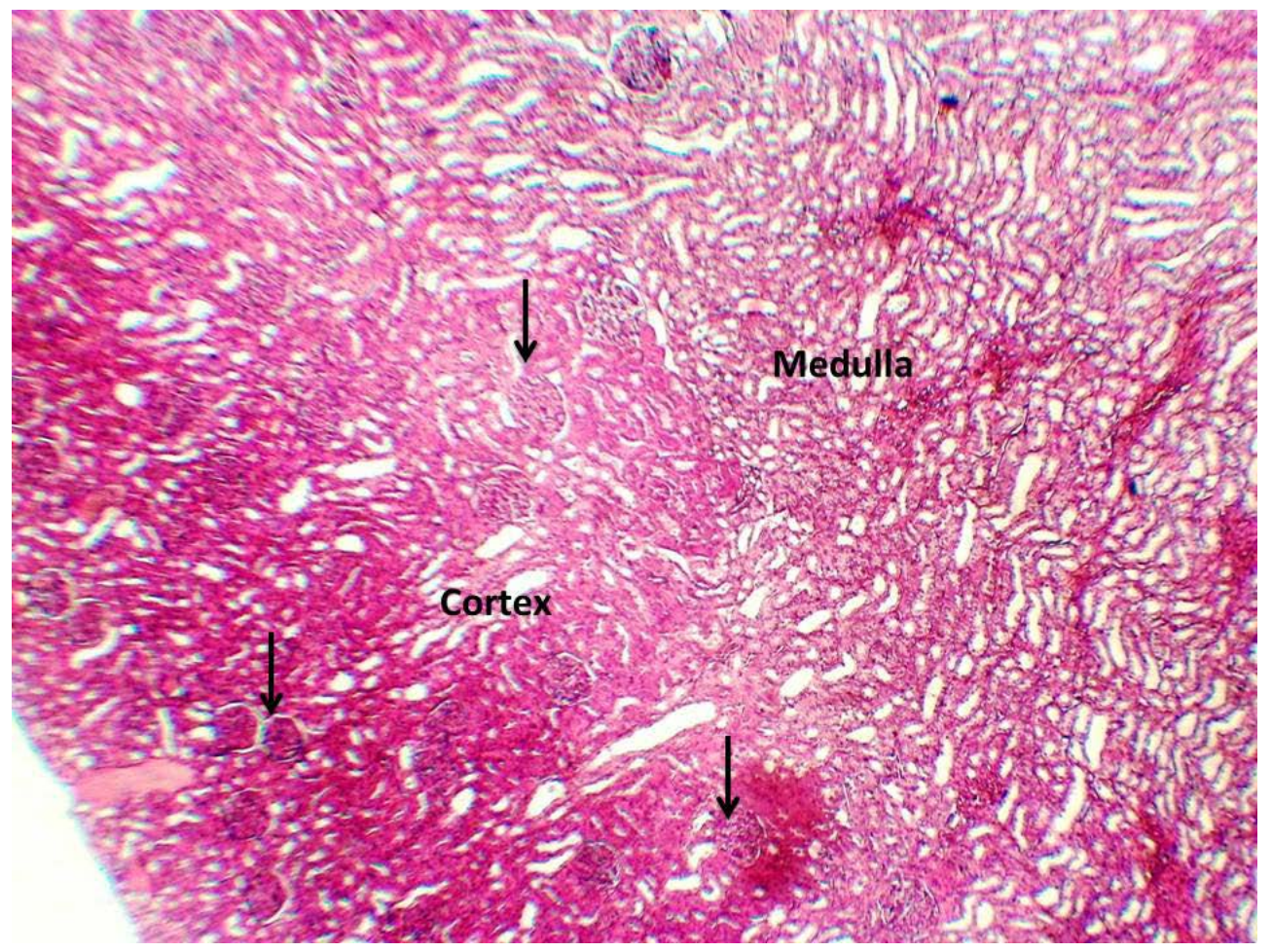

Figure 9. Kidney of grey mongoose showing Cortex, Medulla and Renal corpuscles in cortex (black arrows) H and E stain. 40X. (Hall, 1979) ${ }^{25}$.



Figure 10. Cortex of kidney shows a-Glomerulus, b-Proximal convoluted tubules, d-Distal convoluted tubules, c-Collecting tubules. H and E stain. 400X. (Hussin, 2003)26. 


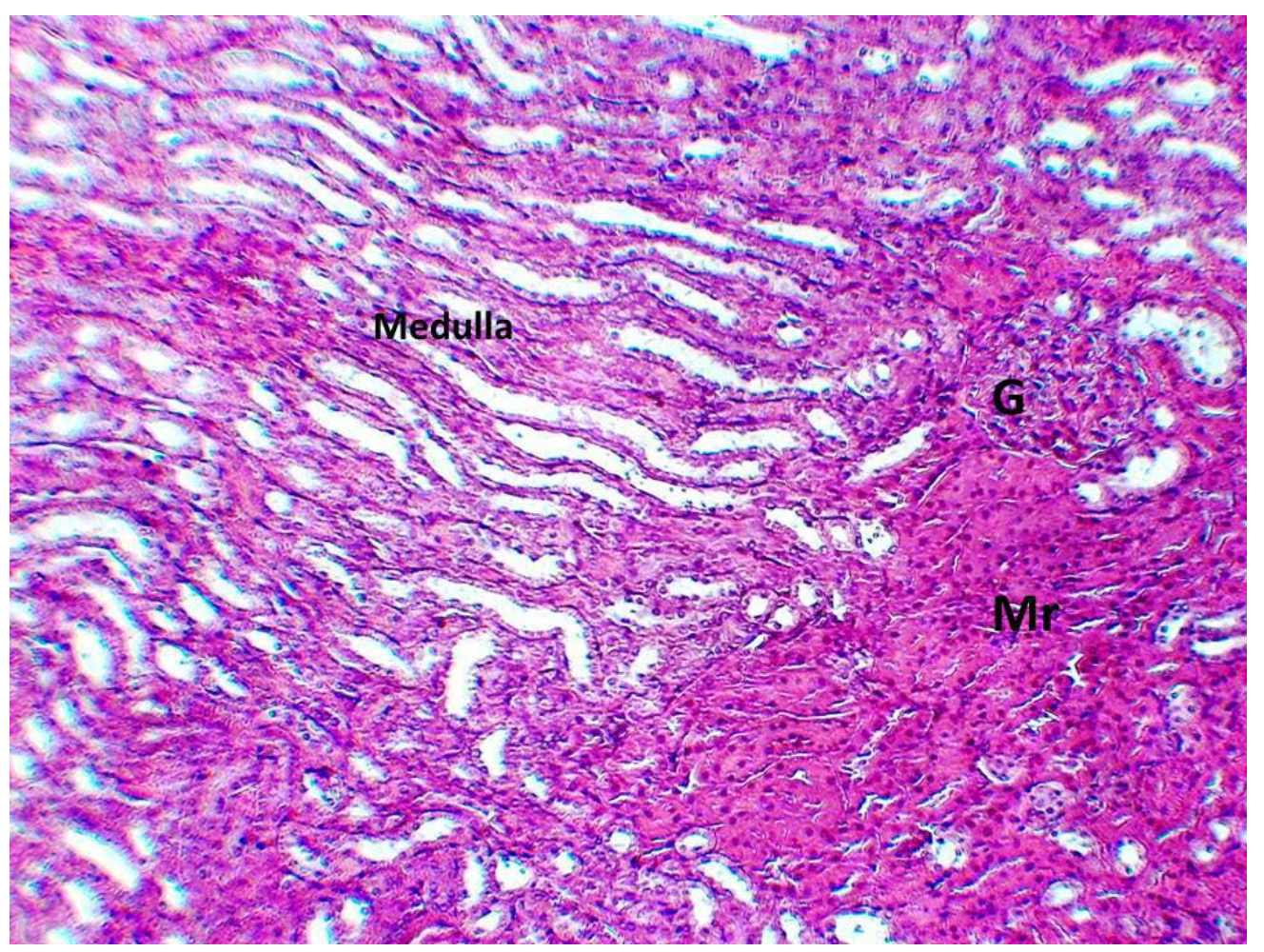

Figure 11. Histological section in cortex of kidney shows G-Renal corpuscle, Mr-Medullary rays. H and E stain. 100X. $(\text { Al-Salami })^{27}$ done.

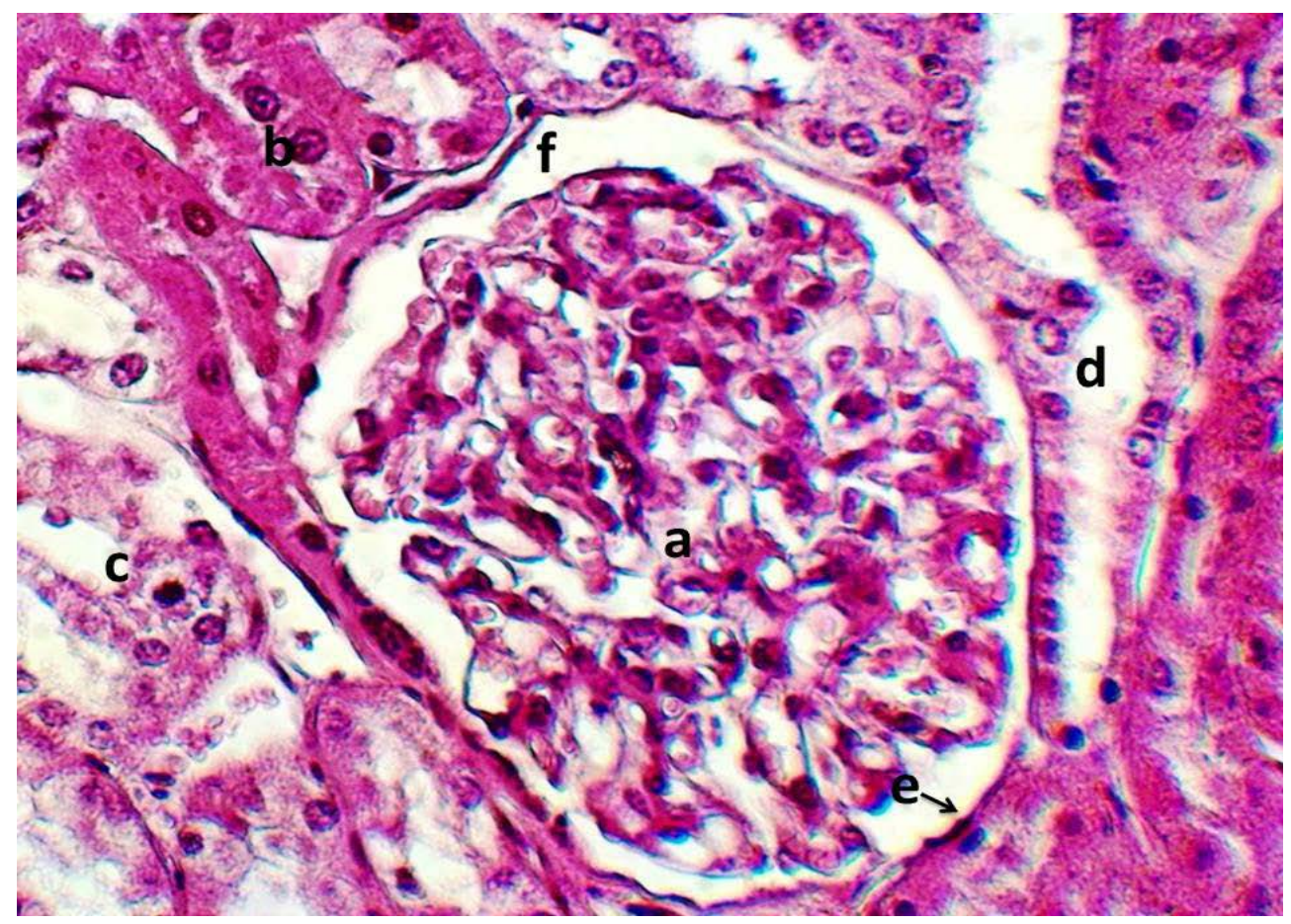

Figure 12. Cortex of kidney showing a-Glomerulus, b-Proximal convoluted tubules, d-Distal convoluted tubules, c-Collecting tubules, e-Bowman space, f-Parietal layer. $\mathrm{H}$ and E stain. 400X. (Samuelson, 2007) $)^{28}$. 


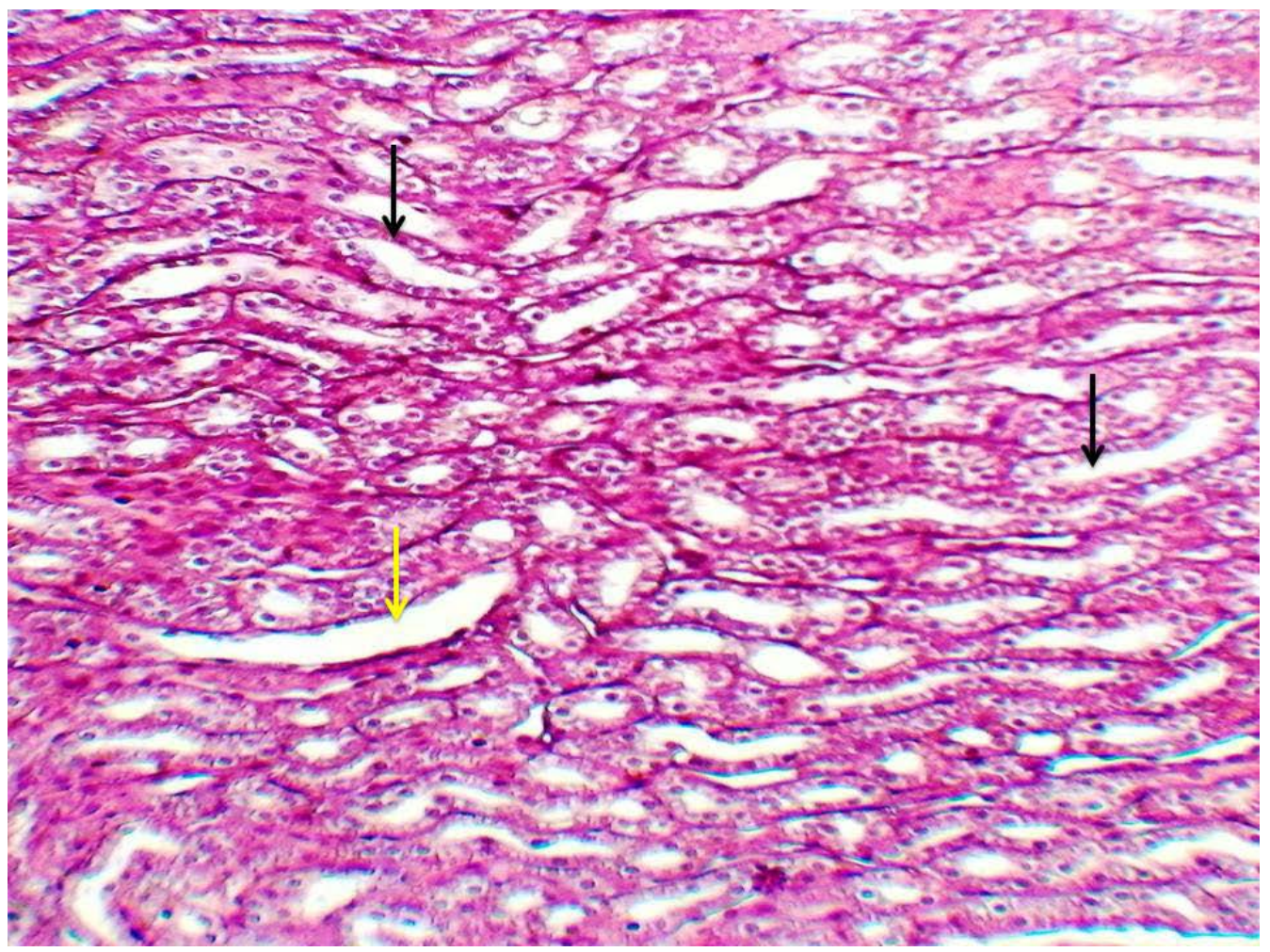

Figure 13. Medulla of kidney shows collecting tubule lined by simple cuboidal epithelia (black arrows) and henle loop (yellow arrow). $\mathrm{H}$ and E stain.100. (Boshra X et al. 2008) ${ }^{29}$.

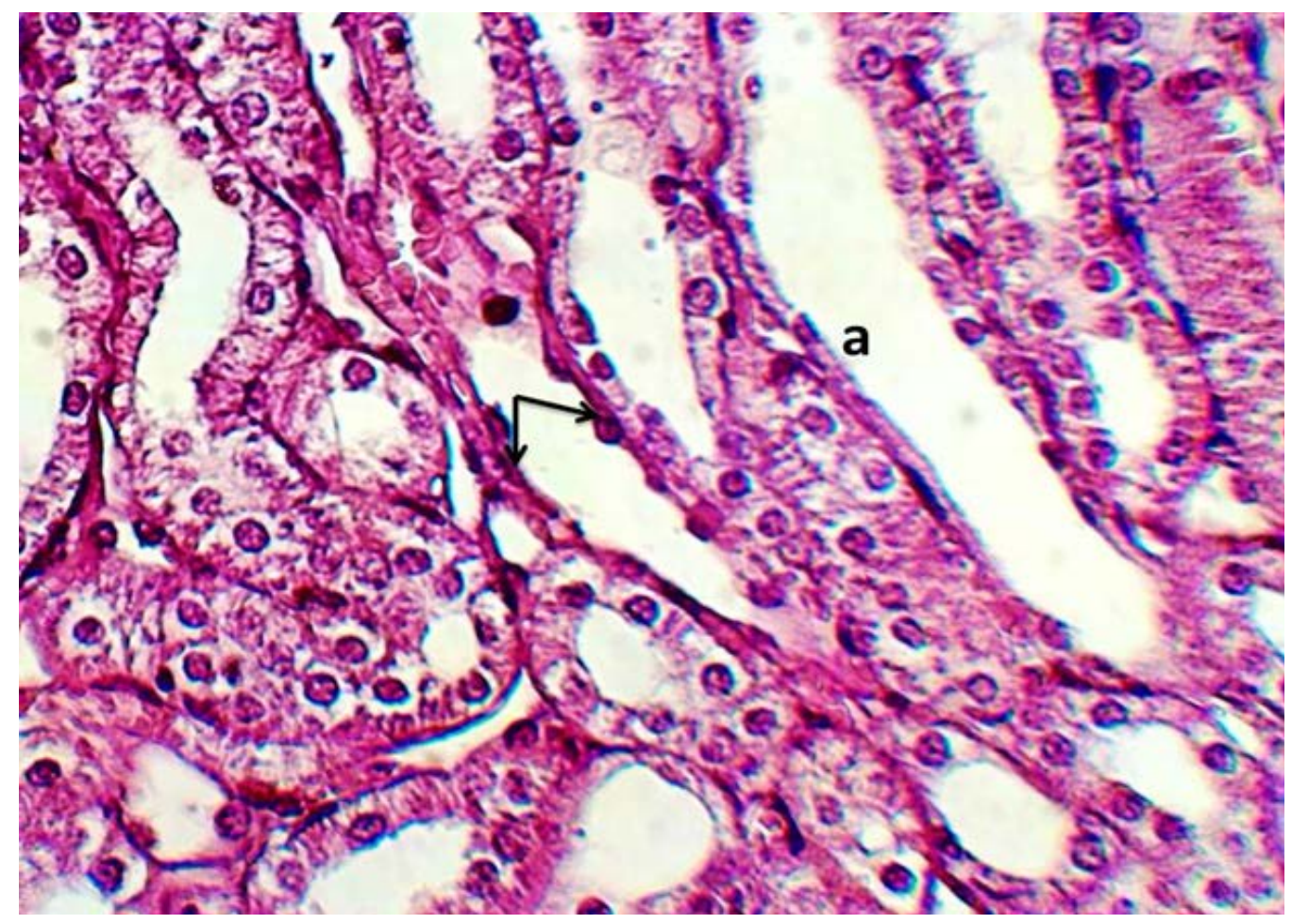

Figure 14. Medulla of kidney shows a-Henle loop had wide lumen contains dark bulge nuclei (black arrow). H and E stain. 400X. (Boshra X et al. 2008) ${ }^{29}$. 


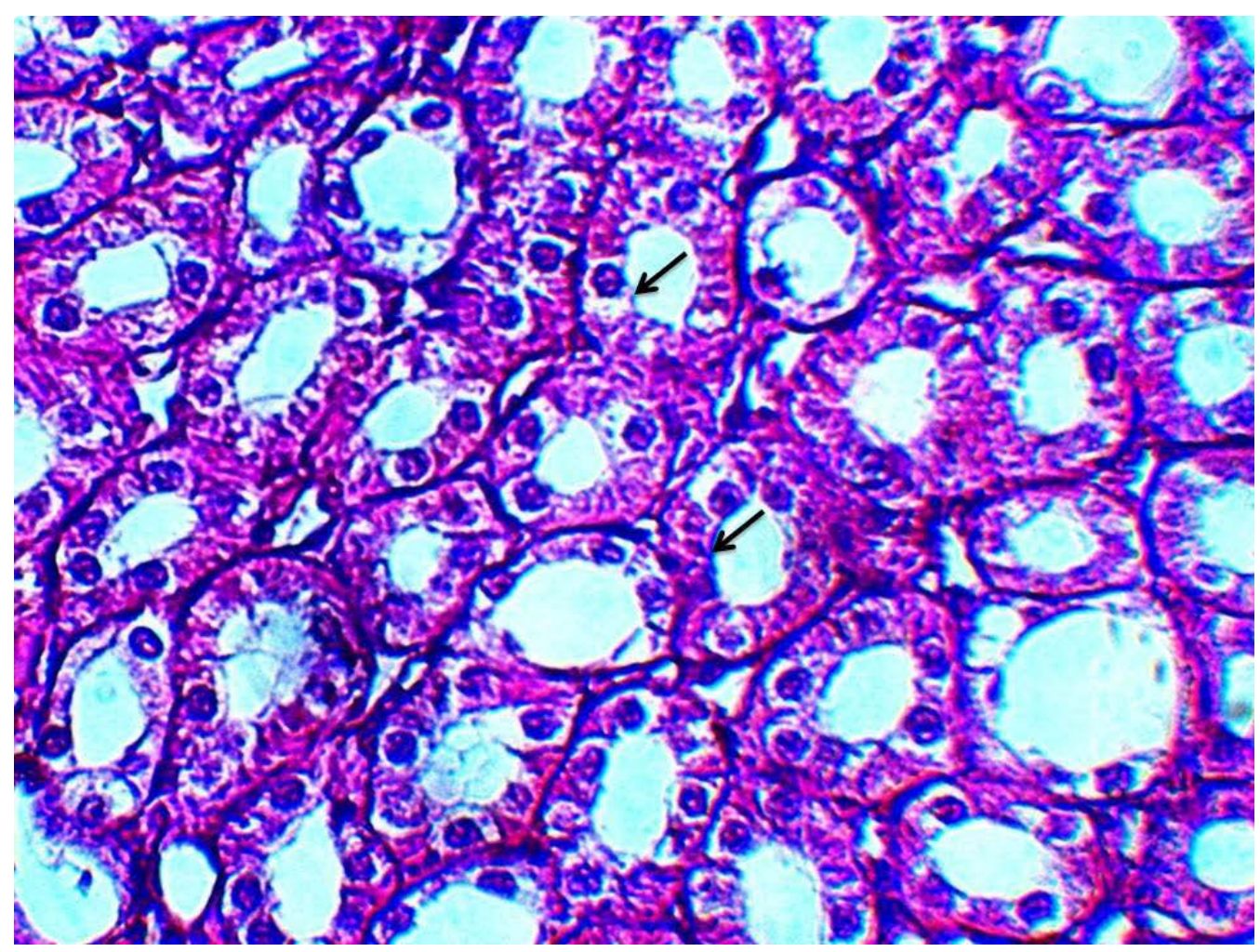

Figure 15. Histological section in medulla of kidney shows papillary ducts lined by simple cuboidal epithelia (black arrows). $\mathrm{H}$ and E stain. 400X. (Hussin, 2003) ${ }^{26}$.



Figure 16. Histological section in cortex of kidney shows moderated reaction for G-Glomeruli and Pt-Proximal tubules and weakly for Dt-Distal tubules. PAS stain. 400X. (Rolan, 1962) ${ }^{31}$. 


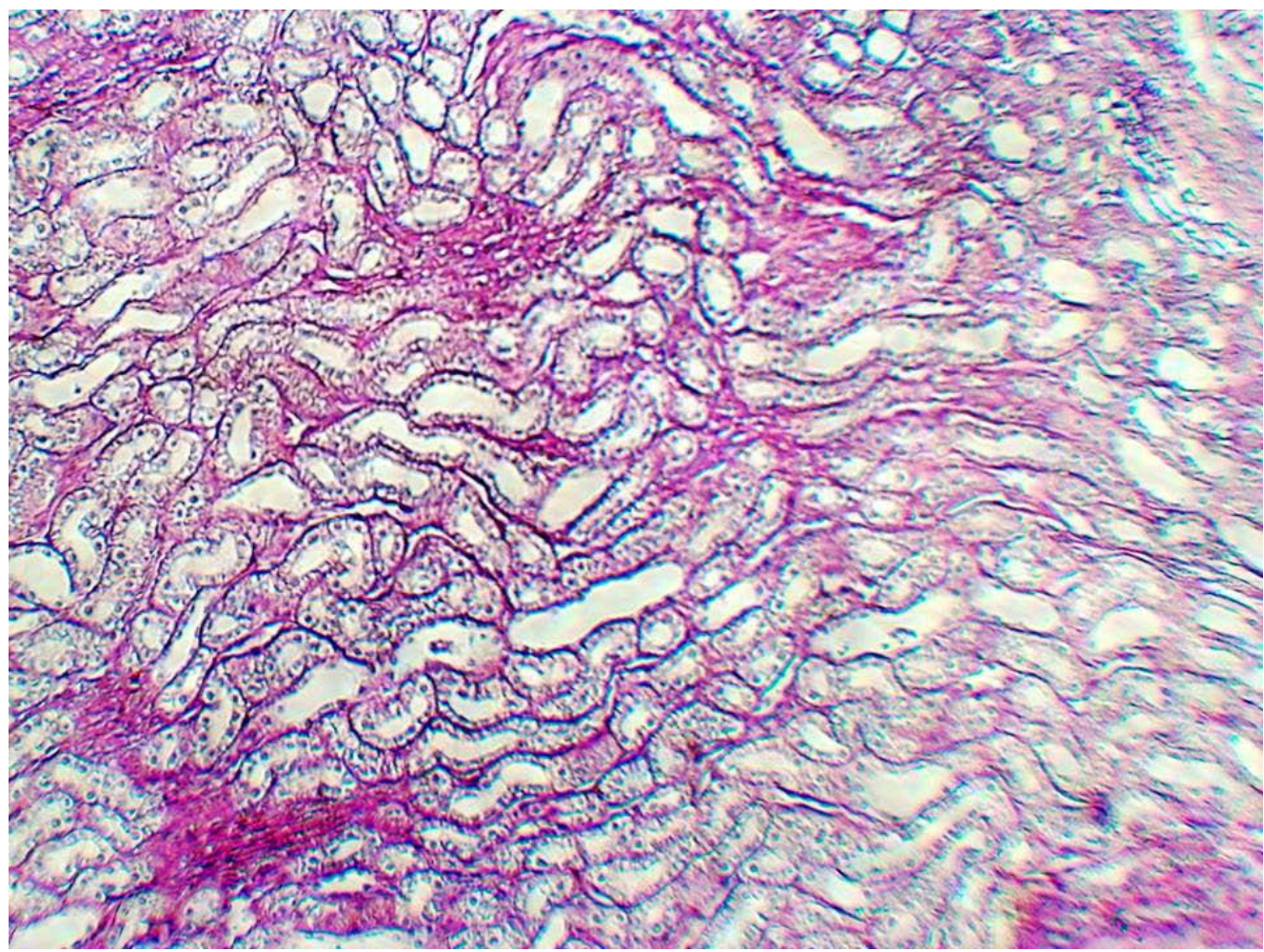

Figure 17. Histological section in medulla of kidney shows weakly reaction in collecting tubules and collecting duct. PAS stain. 10X. (Rolan, 1962) ${ }^{31}$.

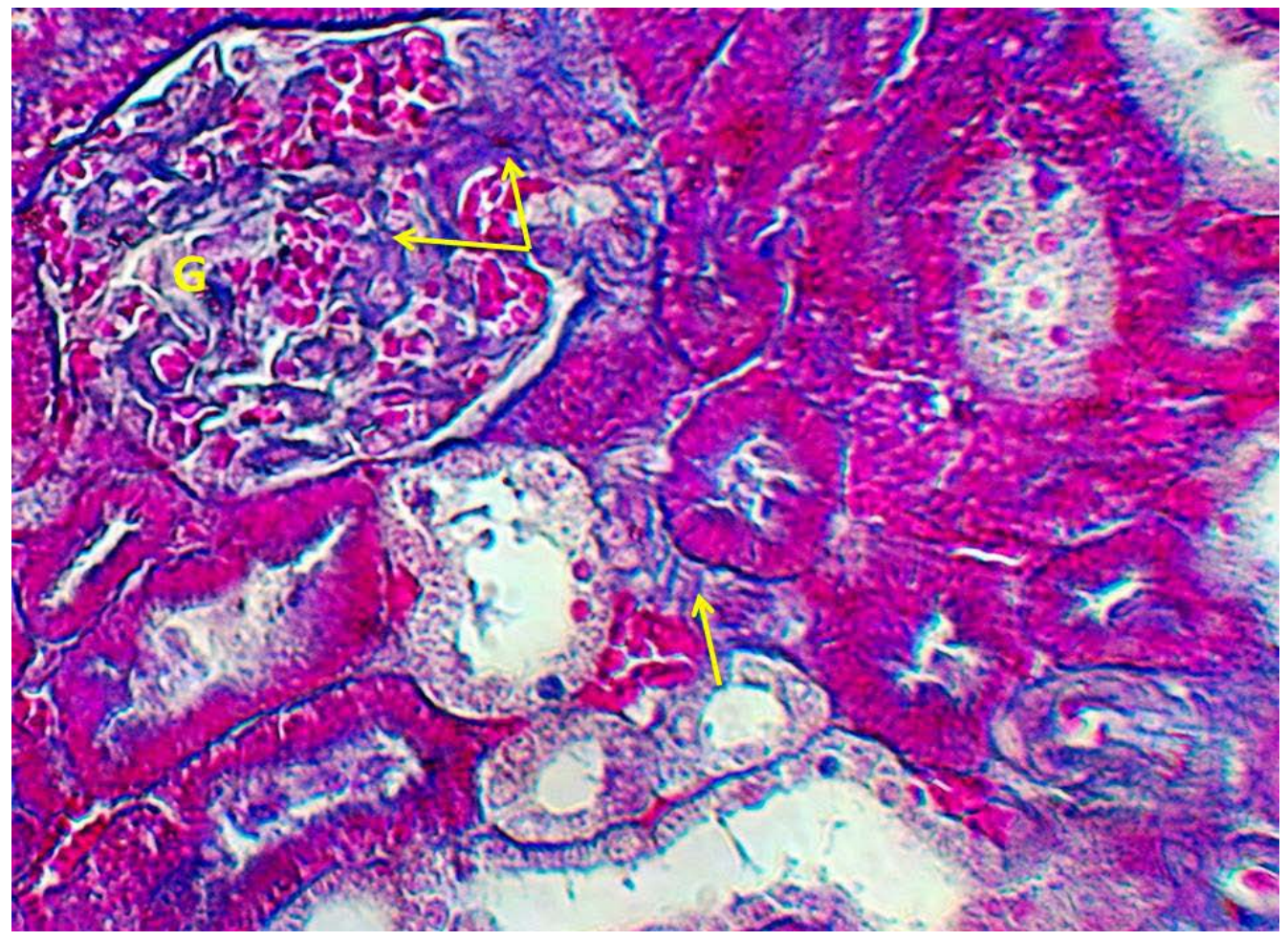

Figure 18. Histological section in cortex of kidney shows large amount of collagen fibers in G-Glomeruli and interstitial tissue (yellow arrows). Masson's trichrome stain. 400X. (Khan et al. 2014) ${ }^{32}$. 


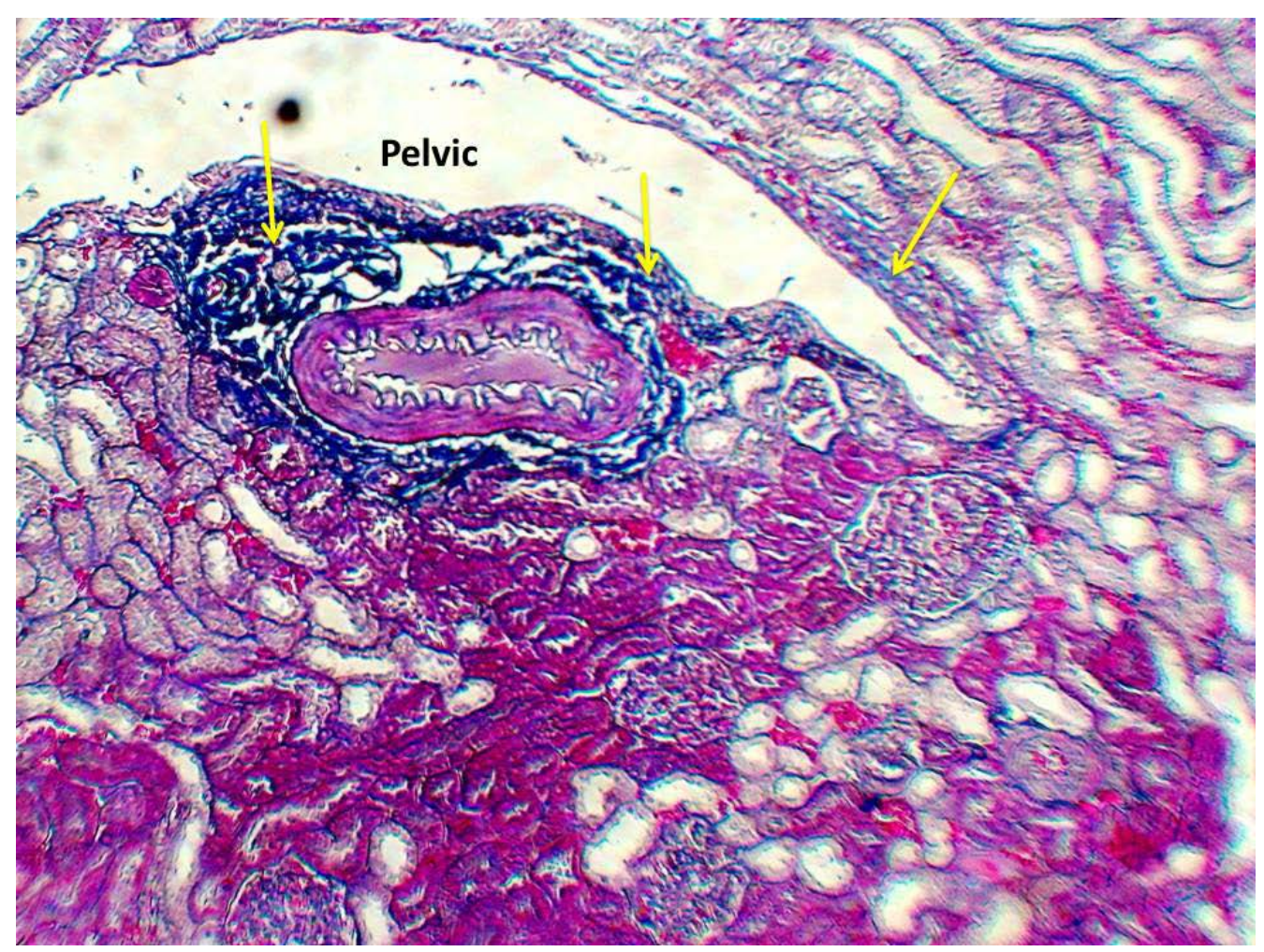

Figure 19. Histological section of kidney shows large amount of collagen fibers in in pelvic region (yellow arrows). Masson's trichrome stain. 400X. (Khan et al. 2014) ${ }^{32}$.

Table 1. The measurements of kidney in grey mongoose (Larson et al. 2009) ${ }^{24}$

\begin{tabular}{|l|l|l|l|l|l|}
\hline Title & Thickness & length & width & Weight & Weight animal \\
\hline Right|kidney & $0.4 \mathrm{~mm}$ & $1.4 \mathrm{~mm}$ & $0.6 \mathrm{~mm}$ & $2.5 \mathrm{gm}$ & $350.4 \mathrm{gm}$ \\
\hline Left|kidney & $0.6 \mathrm{~mm}$ & $1.6 \mathrm{~mm}$ & $0.7 \mathrm{~mm}$ & $2.7 \mathrm{gm}$ & $350.4 \mathrm{gm}$ \\
\hline
\end{tabular}

are not always present. The adventitia was composed of fibrous connective tissue (Figures 20 and 21).

\subsection{Urinary Bladder}

The wall of urinary bladder in grey mongoose consisted of mucosa, submucosa, muscularis externa and serosa. The mucosa of urinary bladder lined by thin 4-5 layers of transitional epithelium rested on lamina propria which composed of thick layers of collagen fibers merged with submucosa layer, the muscularis externa was composed of thick layer of circular smooth muscle, these results disagreement with ${ }^{33}$ who stated that the transitional epithelium is also thick, the epithelium would be much thinner. Also that the thick muscularis is composed of three layers of smooth muscle: (Figures 22 and 23).

\section{Conclusions}

In the present study, we report the left kidney longer than the right and had deferent position. The external surface of kidney was highly vascularized and covered by thin capsule, while the internal surface consist of dark cortex and had one pyramidal rays which opened in single papilla. This result finds that there are two branches of renal artery reach to the right kidney while the left side receive a branch from lateral aspect of aorta. In addition, the histological study explained that the renal corpuscles increased in midcortex and not found in medulla; also, the henle loop in grey mongoose is wide and large as seem to be in carnivores. 


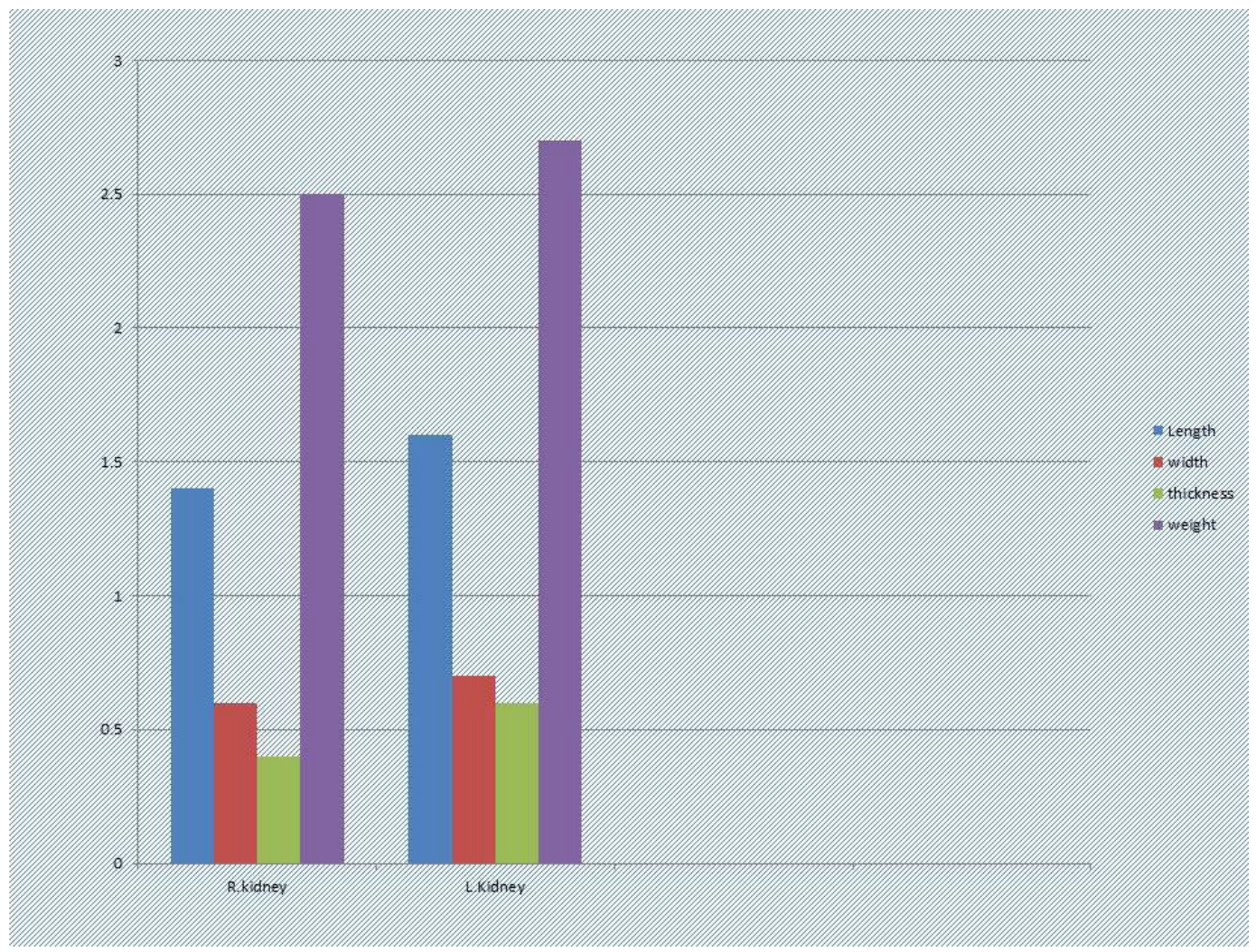

Chart 1. The relative dimensions between Right and Left renal (Larson et al., 2009) ${ }^{24}$

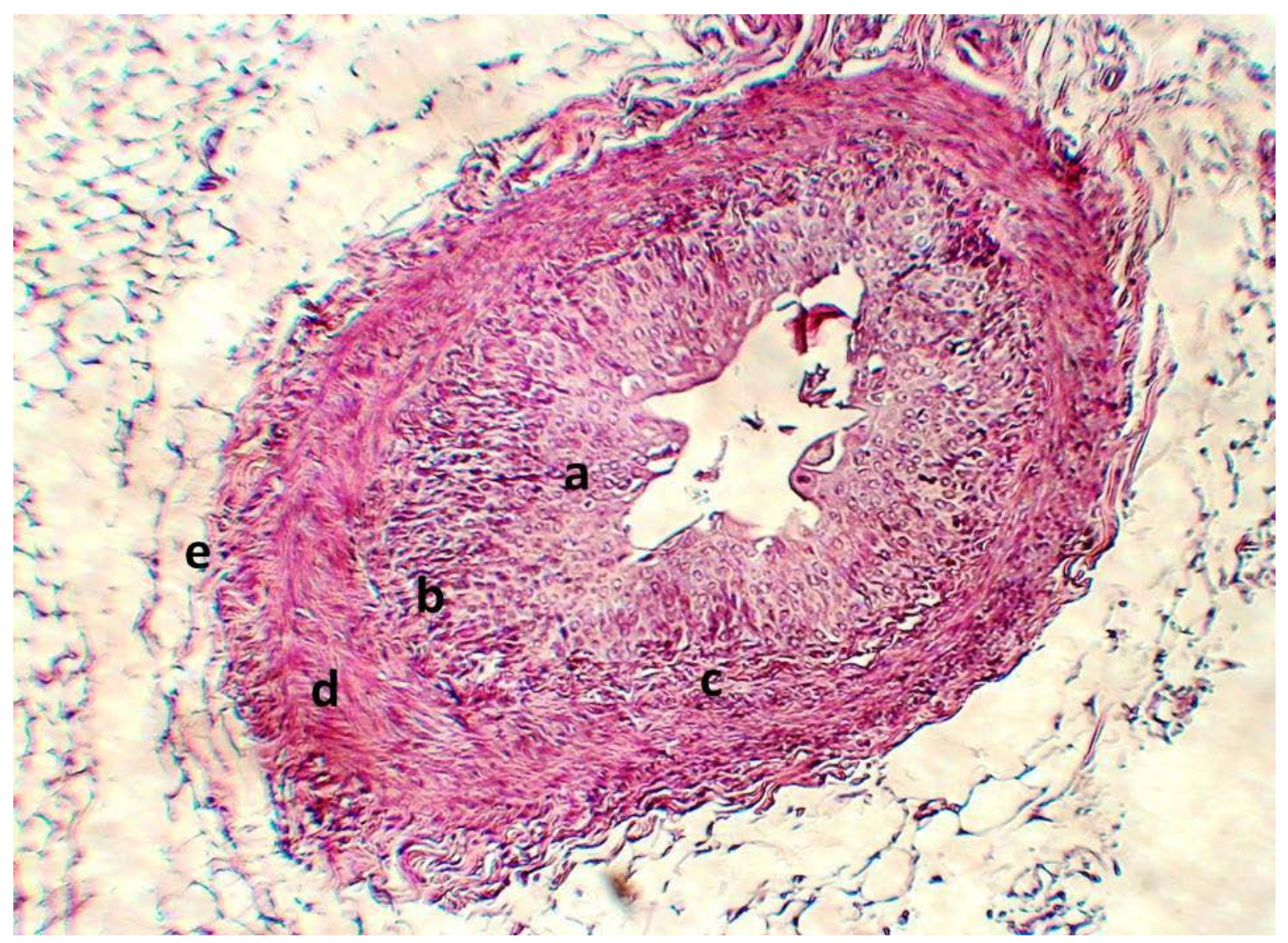

Figure 20. Histological section in ureter shows a-Epithelium, b-Lamina propria, c-Inner longitudinal layer, d-Outer circular layer and e-Adventitia. $\mathrm{H}$ and $\mathrm{E}$ stain. (Leslie and James) ${ }^{33}$. 




Figure 21. Histological section in ureter shows collagen fibers in lamina propria and tunica adventitia (yellow arrows). Masson's trichrome stain. 40X. (Khan et al. 2014) ${ }^{32}$.

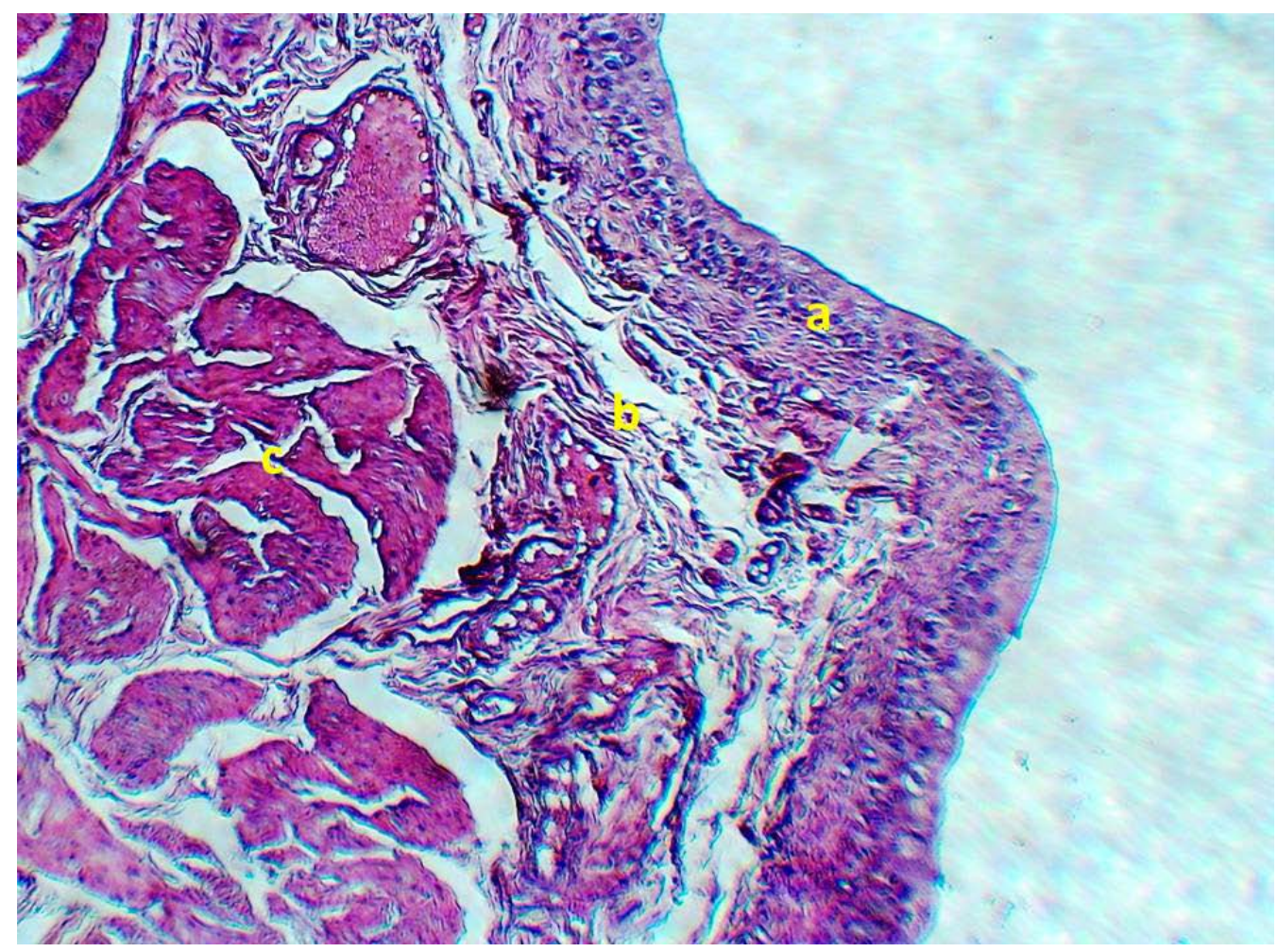

Figure 22. Histological section in ureter shows a-Epithelium, b-Submucosa, c-Muscular layer. H and E stain. 100X. (Leslie and James ${ }^{33}$. 


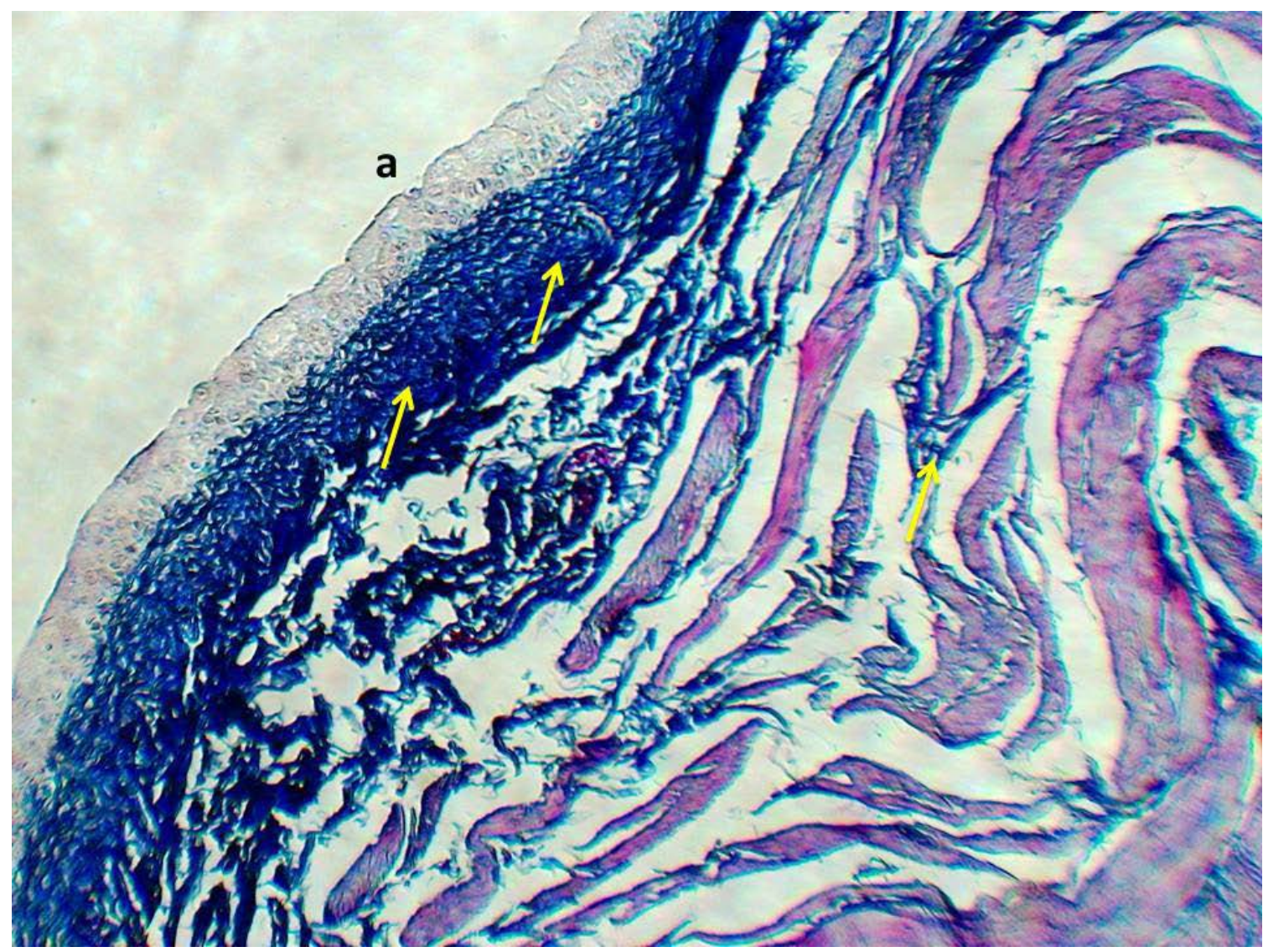

Figure 23. Histological section in ureter shows a-Epithelium and thick layer of collagen fibers in lamina propria and tunica submucosa (yellow arrows). Masson's trichrome stain.100X. (Khan et al. 2014) ${ }^{32 .}$

\section{Acknowledgements}

The first author expresses her gratitude to the Department of anatomy and Histology\Kerbala University and Professor: Khalid. K. Kadhim for supporting this work.

\section{References}

1. Herpestesedwardsii. 2013. http://www.iucnredlist.org

2. Hatt RT. The mammal of Iraq. Publications Museum of Zoology. 1959; 106:1-128.

3. Harison DL. Mammal of Arabia. Harrison Zoological Museum. 1988. p. 1-354.

4. Thulin CG, Simberloff D, Barun A, Pascal M, Islam MA. Genetic divergence in the small Indian mongoose (Herpestesauropunctatus), a widely distributed invasive species. Molecular Ecology. 2006; 15(13):3947-56. PMid: 17054495. https://doi.org/10.1111/ j.1365-294X.2006.03084.x
5. Nowak E, Kuchinka J, Szczurkowski A, Kuder T. Extrahepatic biliary tract in chinchilla (Chinchilla laniger, Molina). Anatomia Histologia Embryologia. 2015; 44(3):236-40. PMid: 25091180. https://doi.org/10.1111/ ahe. 12137

6. Hinton HE, Dunn AMS. Mongooses: Their Natural History and Behavior. Berkeley; 1967. p. 7-144.

7. Herpestes edwardsii. 2013. http://www.iucnredlist.org

8. Corbet GB, Hill JE. World list of mammalian species. Natural History Museum Publications; 1991. p. 1-243.

9. Wells DR. Notes on the distribution and taxonomy of peninsular Malaysian mongooses (Herpestes). Natural History Bulletin of the Siam Society.1989; 37:87-97.

10. Wozencraft WC. Order Carnivora. Oxford University Press; 2005. p. 254-6.

11. Fedorova S, Harada T, Hashimoto H. Renal glomerulogenesis in medaka fish, Oryziaslatipes. Developmental Dynamics. 2008; 237(9):2342-52. PMid: 18729228. https://doi.org/10.1002/dvdy.21687 
12. Pazhayattil G,Shirali A. Drug-induced impairment of renal function. International Journal of Nephrology and Renovascular Disease. 2014; 7:457-68. PMid: 25540591 PMCid: PMC4270362.

13. Lentine KL, Levey AS, Adams PL, Alberu J. KDIGO Clinical practice guideline on the evaluation and care of living kidney donors. 2017; 101:1-105.

14. Yoldas A, Dayan M. Morphological characteristics of renal artery and kidney in rats. Scientific World Journal. 2014. p. 1-7. PMid: 24737971 PMCid: PMC3967660. https://doi.org/10.1155/2014/468982

15. Hickman PC, Roberts SL, Hickman MF. Integrated principles of Zoolgy. Times Mirror: Mosby College Publishing; 1984. p. 1-1065.

16. Gaschen L, Menninger K, Schuurman $\mathrm{H}$. Ultrasonography of the normal kidney in the cynomolgus monkey (Macacafascicularis): Morphologic and doppler findings. Journal of Medical Primatology. 2000; 29(2):76-84. PMid: 10950455. https://doi.org/10.1034/ j.1600-0684.2000.290205.x

17. Thurmon JC, Tranquilli WJ, Benson GJ. Lumb and Jones Veterinary Anesthesia. Anesthesia and Analgesia. 1996; 83(6):1-1354.

18. Theory and Practice of Histological Techniques. 2012. https://www.elsevier.com/books/bancrofts-theoryand-practice-of-histological-techniques-e-book/ suvarna/978-0-7020-5032-9

19. Bundars KD, Mcarthy PH, Frike WE. Anatomy of kidney: Anatomy of the dog. Germany: Schluterscheverlagese; 2010. p. 1-62.

20. Ali F, Ghazi A,Zaid Abd. K. Histological study to the nephrons of the kidney in dogs (Canisfamiliaris) in middle of Iraq. Kufa Veterinary Medicine. 2014; 5(1):98-103.

21. Is there a difference between the right and left kidney? A macroscopic approach in Brazilian Shorthair Cat. 2016. http://www.scielo.br/scielo.php?script=sci_arttext\&pi $\mathrm{d}=$ S010209352016000501137

22. Katrien D, Hendrik, H. Ultrasonography of the feline kidney: Technique, anatomy and changes associated with disease. Journal of Feline Medicine and Surgery.
2012; 14(11):794-803. PMid: 23087005. https://doi. org/10.1177/1098612X12464461

23. Yoldas A, Aydin R. Macroscopic distribution of the renal artery and intrarenal arteries in mole rats (Spalaxleucodon). VeterinarniMedicina. 2014; 59(8):382-7. https://doi. org/10.17221/7658-VETMED

24. Larson M. The kidneys and ureters. O'Brien R and Barr F. BSAVA Manual of canine and feline abdominal imaging. Gloucester: British Small Animal Veterinary Association; 2009. p. 185-204. PMid: 19923569 PMCid: PMC2812081 https://doi.org/10.22233/9781905319718.16

25. Hall. Journal of Animal Anatomy and Physiology.1979. p. 1-280.

26. Hussin A. Seasonal histological changes in kidney of one humped camel Camelus dromedarius in middle of Iraq. Veterinary Medicine. 2003. p. 29-32.

27. Al-Salami NMA. Microscopic study of some parts of urinary system in one-humped dromedary camel specially the kidney. Baghdad University; 1992. p. 19-30.

28. Samuelson DA. Textbook of veterinary histology. Philadelphia: Saunders and Elsevier; 2007. p. 371-4.

29. Boshra A, Mohammad B, Hanaa A. Anatomical, histological and histochemical studies on some organs of true desert rodents in the Egyptian habitats. The Egyptian Journal of Hospital Medicine. 2008; 33(1):306-578.

30. Kader DH, Gabri MS, Ibrahim MA, Hassan BN. Histological and immunohistochemical study on the changes induced by contraceptive pills in the female rabbit's kidney. The Egyptian Journal of Hospital Medicine. 2012; 46(1):47-63.

31. Rolan C. Histology, histochemistry and electron microscopy of the transitional epithelium of the rat urinary bladder in response to induced physiological changes. Acta Anatomica. 1962; 48:297-315. https://doi.org/10.1159/000141848

32. Khan H, Muhammad MR, Ahmad R, Ahmad N, Shah G. Gross anatomical study on normal kidneys of adult goat. Journal of Animal and Veterinary Advances. 2003; 2(9):539-41.

33. Leslie P, James L. Color atlas and text of histology. Maryland; 2014. p. $40-1$. 